\title{
Canadian election goes against the 'green shift'
}

\author{
Canada's voters have rejected the Liberal party's strong environmental platform to re-elect \\ Conservative Prime Minister Stephen Harper. Hannah Hoag looks down the road ahead for \\ Canadian climate policy.
}

C anadian voters re-elected Conservative Prime Minister Stephen Harper in their 14 October federal election, granting the Conservatives 19 more seats than they had after the last election in 2006. The news is sobering for those with climate change at the top of their list of concerns. The Conservative government has been criticized for its weak environmental policies; all the competing parties had much stronger platforms on cutting greenhouse gas emissions.

In the initial weeks of campaigning in September, green issues dominated Canada's election debate. The opposition Liberal party (centre-left) leader

Stéphane Dion staked his campaign on an environmental platform called the 'Green Shift' (see Nature 455, 268; 2008), which would have shifted taxes away from income and onto fossil fuels. Overall the Liberal party platform aimed to reduce greenhouse gas emissions to at least 20 per cent below 1990 levels by 2020. The three other left-ofcentre political parties called for some mix of carbon taxes, cap-and-trade schemes and plans to meet the emissions reductions called for by the Kyoto Protocol. The Conservative party (centre-right) based most of its campaign on economic issues. With regard to the environment, they have pledged to cut emissions to 20 per cent below 2006 levels by 2020, the equivalent of just a 3-per-cent reduction from 1990 levels.

A week before the election, more than 120 top scientists published an open letter that urged Canadians to vote for the environment. With the global economic crisis worsening, "it was an attempt to bring the issue of the environment back into people's minds," says John Smol, a limnologist at Queen's University in Kingston, Ontario, and a co-signer of the document. The letter criticized the country's obstruction of international

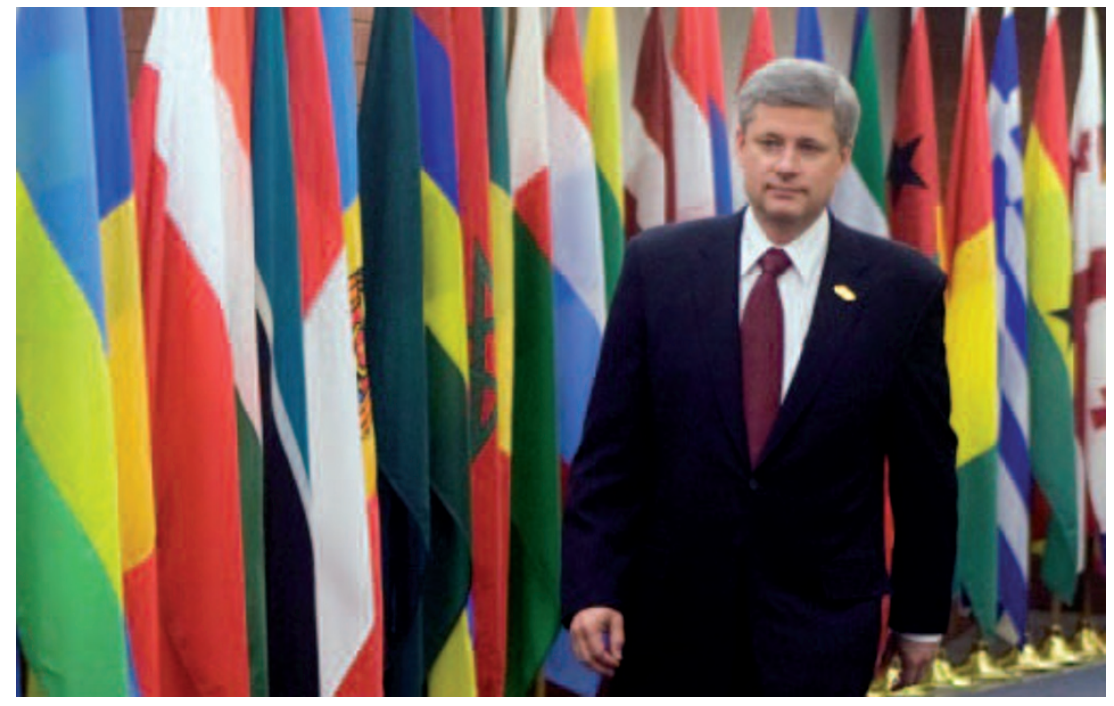

Stephen Harper.

efforts to deal with global warming, including at the UN meeting in Bali in December 2007. Canada tied with the United States in winning 14 'Fossil of the Day' awards from an environmental group at that conference, in recognition of their attempts to block progress.

Underwhelmed by the Conservative position on climate change, environmentally concerned Canadians spawned new websites and Facebook groups that aimed to block Harper's re-election by encouraging strategic voting and vote swapping. One of the biggest, Vote for Environment (http://www.voteforenvironment.ca), identified swing ridings where a 'pro-environment' candidate could win if one-third of non-conservative voters strategically piled their votes onto the one strongest alternative candidate.

As it turned out, although more than 60 per cent of Canadians did not vote Conservative, their votes were split among too many parties to keep Harper out of power. Conservatives won the greatest number of seats of any party, but slightly less than half of the 308 total available seats, giving them a minority government (with 143 Conservative seats against 76 Liberal). Under the Vote for Environment scheme, had non-conservative voters been compelled by environmental issues to follow the website's recommendation, the result would have established a Liberal minority government (with 128 Liberal seats against 67 Conservative).

"We had hoped that people would vote strategically, but we didn't see that," says John Stone, past Vice Chair of Working Group II of the Intergovernmental Panel on Climate Change and a climate change specialist at Carleton University, in Ottawa. Last year, climate change issues proved a strong enough campaign issue in Australia to force out their Conservative government. 
Canada faces important domestic and international environmental policy decisions in the next two years. At home, the development of the Alberta oil sands remains highly contentious. The operation, which produces more than a million barrels of oil a day, uses large amounts of water and energy for the oil extraction and generates vast quantities of waste water. Conservative policies require carbon capture and storage for oil-sands operations, but only for those beginning after 2012. "The federal government has designed a plan that does a better job of accommodating the oil companies," says Graham Saul, executive director at the non-partisan Climate Action Network Canada, in Ottawa.
Negotiations over international actions on climate change are set to continue at the fourteenth Conference of the Parties to the Climate Change Convention in Poznan, Poland, this December and wrap up in Copenhagen in December 2009, where a successor to the 1997 Kyoto agreement - which expires in 2012 - will be decided. Given Canada's history and the new election results, observers say it seems the nation won't be leading such efforts. "Canada will respond to international pressures, but we won't be writing the script," says Stone. "It's a pity. We're going to be left on the wrong side of history."

Climate scientists are sceptical that Harper will alter his stance on environmental policy issues, but they remain hopeful. In a move that surprised many, Harper announced on 19 October that Canada would dedicate C\$100 million to help developing countries deal with climate change. The upcoming speech from the throne, which will officially open a new session of Parliament and lay out the government's broad goals, perhaps as soon as early November, should shed light on how environmental issues will be tackled.

\section{Published online: 30 0ctober 2008}

doi:10.1038/climate.2008.116

Hannah Hoag is a freelance science writer.

\section{nature geoscience}

\section{Submit online now!}

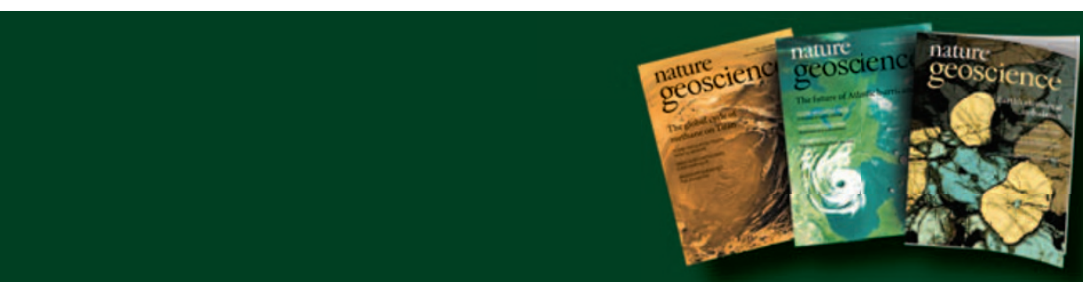

Chief Editor: Heike Langenberg PhD

Associate Editors: Ninad Bondre, PhD; Alicia Newton, PhD and Anna Armstrong, PhD

Nature Geoscience is a new international forum for the timely publication of significant new research in the geosciences. This monthly journal is aimed at a broad interdisciplinary audience of scientists from all areas of the Earth and planetary sciences. Nature Geoscience is committed to publishing top-quality original research in the geosciences through a fair and rapid review process.

In addition to publishing primary research, the journal provides an overview of the most important developments in the Earth sciences through the publication of Review Articles, News and Views, Research Highlights, Commentaries and reviews of relevant books and arts events.

Nature Geoscience also provides Advance Online Publication (AOP) of research articles, which benefits authors with an earlier publication date and allows readers access to accepted papers before they appear in print.

Complete submission information is available at:

http://www.nature.com/ngeo/authors/index.html

General editorial inquiries and correspondence should be addressed to the Editor at:geosciencelanature.com 